\title{
Impacts of the spatial extent of pollen-climate calibration-set on the absolute values, range and trends of reconstructed Holocene precipitation
}

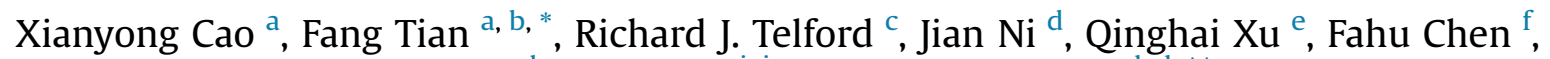 \\ Xingqi Liu ${ }^{g}$, Martina Stebich ${ }^{\mathrm{h}}$, Yan Zhao ${ }^{\mathrm{i}, \mathrm{j}}$, Ulrike Herzschuh ${ }^{\mathrm{a}, \mathrm{k}, \mathrm{l},{ }^{* *}}$ \\ ${ }^{a}$ Alfred Wegener Institute Helmholtz Center for Polar and Marine Research, Research Unit Potsdam, Telegrafenberg A43, Potsdam, 14473, Germany \\ ${ }^{\mathrm{b}}$ Max Planck Institute for Meteorology, KlimaCampus, Bundesstrasse 53, Hamburg 20146, Germany \\ ${ }^{c}$ EECRG, Department of Biology, University of Bergen, Bjerknes Centre for Climate Research, PO Box 7803, N-5020 Bergen, Norway \\ ${ }^{\mathrm{d}}$ College of Chemistry and Life Sciences, Zhejiang Normal University, Yingbin Avenue 688, 321004 Jinhua, China \\ e College of Resources and Environment Sciences, Hebei Normal University, Shijiazhuang 050024, China \\ ${ }^{\mathrm{f}}$ Institute of Tibetan Plateau Research, Chinese Academy of Science, Beijing 100101, China \\ $\mathrm{g}$ Beijing Key Laboratory of Resource Environment and GIS, College of Resource Environment and Tourism, Capital Normal University, Beijing 100048, China \\ h Senckenberg Research Station for Quaternary Palaeontology, Am Jakobskirchhof 4, D-99423 Weimar, Germany \\ ${ }^{\mathrm{i}}$ Institute of Geographic Sciences and Natural Resources Research, Chinese Academy of Sciences, Datun Road 11, Beijing 100101, China \\ ${ }^{\mathrm{j}}$ University of Chinese Academy of Sciences, Yuquan Road 19, Beijing 100049, China \\ ${ }^{\mathrm{k}}$ Institute of Earth and Environmental Sciences, University of Potsdam, Karl-Liebknecht-Str. 24/25, 14476 Potsdam, Germany \\ ${ }^{1}$ Institute of Biochemistry and Biology, University of Potsdam, Karl-Liebknecht-Str. 24/25, 14476 Potsdam, Germany
}

\section{A R T I C L E I N F O}

\section{Article history:}

Received 7 July 2017

Received in revised form

20 October 2017

Accepted 21 October 2017

\section{Keywords:}

Analogue quality

Statistical significance

Cross-validation

Holocene

Climate reconstruction

WA-PLS

MAT

\begin{abstract}
A B S T R A C T
Pollen-based quantitative reconstructions of past climate variables is a standard palaeoclimatic approach. Despite knowing that the spatial extent of the calibration-set affects the reconstruction result, guidance is lacking as to how to determine a suitable spatial extent of the pollen-climate calibration-set. In this study, past mean annual precipitation $\left(\mathrm{P}_{\mathrm{ann}}\right)$ during the Holocene (since $11.5 \mathrm{cal} \mathrm{ka} \mathrm{BP}$ ) is reconstructed repeatedly for pollen records from Qinghai Lake $\left(36.7^{\circ} \mathrm{N}, 100.5^{\circ} \mathrm{E}\right.$; north-east Tibetan Plateau), Gonghai Lake $\left(38.9^{\circ} \mathrm{N}, 112.2^{\circ} \mathrm{E}\right.$; north China) and Sihailongwan Lake $\left(42.3^{\circ} \mathrm{N}, 126.6^{\circ} \mathrm{E}\right.$; north-east China) using calibration-sets of varying spatial extents extracted from the modern pollen dataset of China and Mongolia (2559 sampling sites and 168 pollen taxa in total). Results indicate that the spatial extent of the calibration-set has a strong impact on model performance, analogue quality and reconstruction diagnostics (absolute value, range, trend, optimum). Generally, these effects are stronger with the modern analogue technique (MAT) than with weighted averaging partial least squares (WA-PLS). With respect to fossil spectra from northern China, the spatial extent of calibration-sets should be restricted to radii between ca. 1000 and $1500 \mathrm{~km}$ because small-scale calibration-sets ( $<800 \mathrm{~km}$ radius) will likely fail to include enough spatial variation in the modern pollen assemblages to reflect the temporal range shifts during the Holocene, while too broad a scale calibration-set ( $>1500 \mathrm{~km}$ radius) will include taxa with very different pollen-climate relationships.
\end{abstract}

(c) 2017 Elsevier Ltd. All rights reserved.

\footnotetext{
* Corresponding author. Alfred Wegener Institute Helmholtz Center for Polar and Marine Research, Research Unit Potsdam, Telegrafenberg A43, Potsdam, 14473, Germany.

** Corresponding author. Alfred Wegener Institute Helmholtz Center for Polar and Marine Research, Research Unit Potsdam, Telegrafenberg A43, Potsdam, 14473, Germany.

E-mail addresses: fang.tian@awi.de (F. Tian), Ulrike.Herzschuh@awi.de (U. Herzschuh).
}

\section{Introduction}

Quantitative climate reconstructions using modern pollenclimate relationships have been widely applied to investigate past climate change. This approach is based on various assumptions. Among others, it is assumed that pollen taxa recorded in the calibration-set have similar ecological requirements as those in the fossil spectra (Birks et al., 1990, 2010; Juggins and Birks, 2012). As 
pollen are commonly only identified to genus level (most tree and shrub taxa) or family level (most of the herbaceous taxa), the selection of the spatial extent of the calibration-set defines which plant species (and sub-species) determines the taxon-environment relationship of a certain pollen taxon (Williams and Shuman, 2008). For example, it has been concluded that the obvious regional differences in pollen taxa-climate relationships between the eastern Tibetan Plateau and central-northern China of Cyperaceae, Picea and Pinus originate from the specific plant species ensemble covered by a pollen taxon (i.e. Kobresia vs. Carex; Picea asperata vs. Picea meyeri; Pinus densata vs. Pinus tabuliformis, respectively) (Tian et al., 2017). Likewise, Quercus is restricted to the wet end of the moisture gradient in eastern North America, while it prefers arid/ semi-arid climate conditions in the western part (Williams and Shuman, 2008). Furthermore, the pollen-climate relationship may also be dependent on the length of the climatic gradient. For example, Poaceae has a significant relationship with $P_{a n n}$ and the mean temperature of the warmest month (increasing and decreasing, respectively) in a regional-scale modern pollen data-set from Mongolia revealed by Huisman-Olff-Fresco modelling (Tian et al., 2014), while it shows no response to these two climatic variables at a continental scale in eastern Asia (including Mongolia; Cao et al., 2014). Accordingly, the spatial extent of a calibration-set needs to be thoroughly considered. On the one hand, a calibrationset with too small a spatial extent risks that the temporal changes in the fossil pollen spectra cannot be covered by the spatial variation in the modern pollen assemblages (without high quality modern analogues for fossil pollen samples), but on the other hand, too large a spatial extent of the calibration-set will weaken or even distort taxon-climate relationships because various plant species that differ in their climate envelopes are represented by a single pollen taxon.

Weighted averaging partial least squares (WA-PLS) and the modern analogue technique (MAT) are the most common methods used for quantitative climate reconstruction based on pollen data (Juggins and Birks, 2012). The prediction strength of these methods is usually assessed by the coefficient of determination between observed and predicted environmental values $\left(\mathrm{r}^{2}\right)$ and the root mean square error of prediction (RMSEP) as derived by cross-validation. The spatial extent of a calibration-set may affect these parameters, particularly $\mathrm{r}^{2}$ (Birks, 1998), and a large spatial extent of the calibration-set will raise RMSEP since the pollen assemblage heterogeneity increases (Kucera et al., 2005; Cao et al., 2014). For weighted-averaging based methods, the inevitable overestimate and underestimate at environmental gradient ends ("edge effects") have lower impact for the reconstruction when the target environmental gradient is long and the spatial extent of the calibration-set is large (Birks, 1998; Birks and Seppä, 2004). The basic requirement of analogue-based methods is that similar biological assemblages are deposited under similar environmental conditions (Juggins and Birks, 2012). However, the risk for multiple analogues (i.e. similar modern biological assemblages were deposited under different environmental conditions) increases with the spatial extent of the calibration-set, raising the prediction error (Birks et al., 2010). Hence, it is recommended to tailor the calibration-set with respect to spatial extent or environmental gradient for the specific reconstruction (e.g. Birks and Seppä, 2004; Birks et al., 2010; Juggins and Birks, 2012; Chen et al., 2015).

Besides the cross-validation indices ( $r^{2}$ and RMSEP), the tailored calibration-set should also be assessed by the analogue quality and pass the statistical significance test for the target reconstruction. It can be assumed that quantitative climate reconstructions for fossil pollen assemblages that have good analogues in the calibration-set are more reliable than those that have no close analogues (Birks et al., 1990). It also needs to be verified whether the reconstructed climate, inferred by the application of a modern pollen-climate model of a certain spatial extent, best explains a sufficient amount of the variance in the fossil data by assessment with a statistical significance test (Telford and Birks, 2011).

Eastern continental Asia is a suitable region to investigate methodological aspects of pollen-based quantitative climate reconstruction. First, it is a hotspot for the establishment and application of pollen-climate relationships aiming to reconstruct climate as a contribution to the highly debated topic of the spatialtemporal variability of the East Asian Summer Monsoon (e.g. Herzschuh, 2006; Wang et al., 2010; Liu et al., 2015). In the past decade, numerous pollen-environment calibration-sets at both a regional scale (e.g. Shen et al., 2006; Herzschuh et al., 2010; Xu et al., 2010; Tian et al., 2014) and a sub-continental scale have been applied (e.g. Stebich et al., 2015; Li et al., 2016, 2017a, 2017b). Second, eastern continental Asia is characterised by complex climate, topography and vegetation (Hou, 1983; Tao and Chen, 1987), which harbour long climate gradients in biogeographically different regions, such as north-central China and the eastern Tibetan Plateau. Hence, pollen-based reconstructions from eastern continental Asia should be particularly sensitive to the selection of the spatial extent of the calibration-set.

A sub-continental scale modern pollen-climate dataset from eastern continental Asia (including China and Mongolia) has been established, and $\mathrm{P}_{\mathrm{ann}}$ has been confirmed as the most important climatic determinant of pollen distribution (Cao et al., 2014), which has also been revealed by regional pollen-climate calibration-sets (Shen et al., 2006; Herzschuh et al., 2010; Xu et al., 2010; Tian et al., 2014). In this study, we employ the modern pollen-climate dataset from eastern continental Asia (Cao et al., 2014) to reconstruct $P_{a n n}$ for three high-resolution Holocene pollen records from northern China (Qinghai Lake, Liu et al., 2002; Gonghai Lake, Chen et al., 2015; and Sihailongwan Lake, Stebich et al., 2015) repeatedly, using calibration-sets of varying spatial extent. In particular, we investigate the impact of the spatial extent of the calibration-set on the pollen-climate model performance, analogue quality and reconstruction diagnostics (including absolute values, range, trend, and optimum).

\section{Data and methods}

\subsection{Pollen and climate datasets}

The modern pollen dataset from China and Mongolia comprises 2559 sampling sites (including soil-surface, lake sediment-surface, dust and moss samples; Fig. 1; Cao et al., 2014) and 168 major pollen taxa (those present in at least 3 samples and with $\geq 3 \%$ in at least one sample; Cao et al., 2014). Pollen names have been taxonomically harmonised. Canonical correspondence analysis suggests that $\mathrm{P}_{\mathrm{ann}}$ has the strongest influence on pollen composition across the entire dataset (Cao et al., 2014). Around $80 \%$ of $\mathrm{P}_{\mathrm{ann}}$ in monsoonal areas comprises summer rainfall (as revealed by the climate data of the 2559 pollen sites), and thus, given the reservoir function of soil, $P_{a n n}$ should be comprehensive in representing the moisture situation in northern China. Hence, we selected $P_{a n n}$ as the target variable for our quantitative reconstructions, which means the reconstructions are directly comparable with previous pollen-climate studies.

To explore the impact of the spatial extent of the calibrationset on reconstruction, three high-quality target fossil pollen records were selected that have previously been used for climate reconstructions. They originate from different regions in northern China within the area marginally affected by the East Asian 


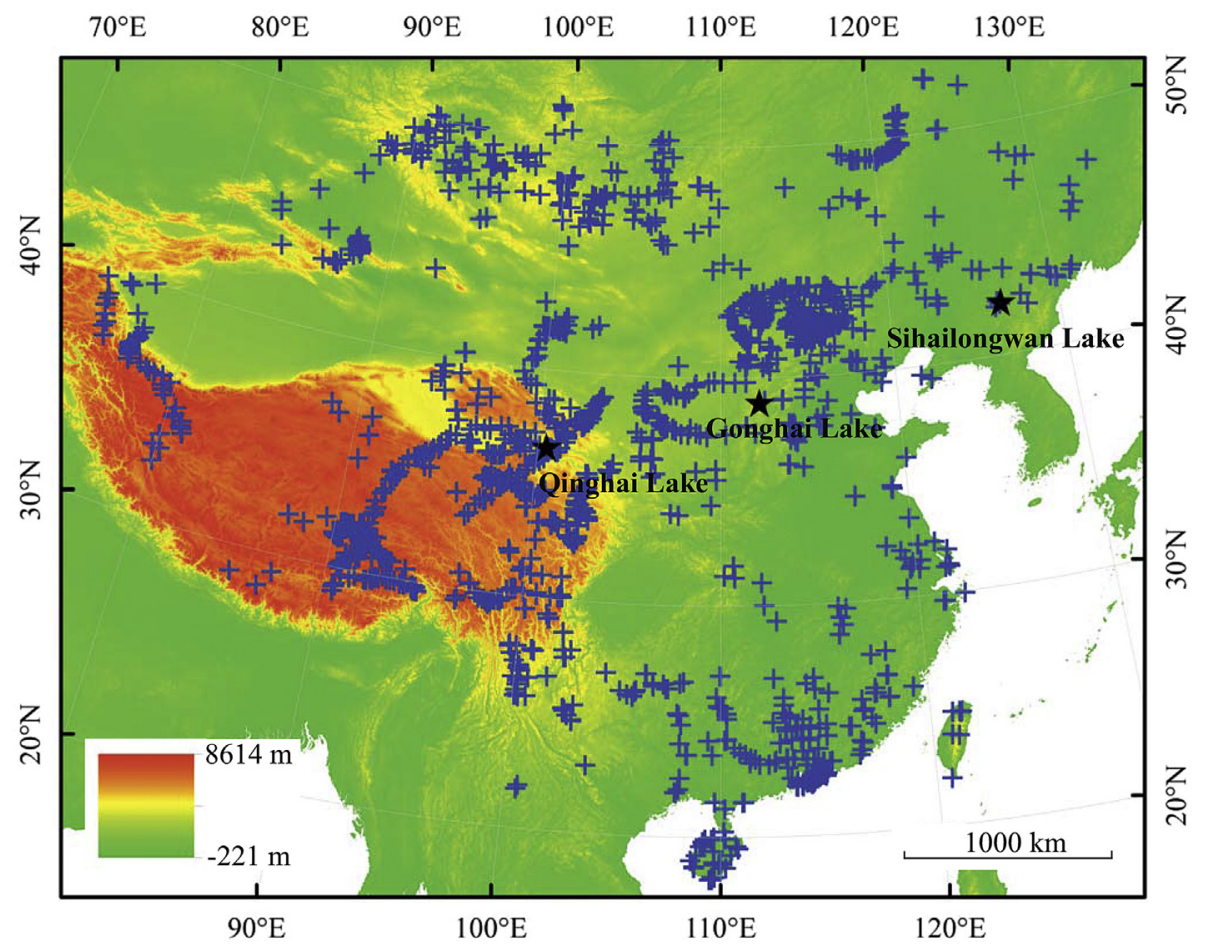

Fig. 1. Location of modern pollen sample sites (crosses) and the three target fossil pollen records (stars).

Summer Monsoon where precipitation is particularly sensitive to circulation changes (e.g. Ding et al., 2008). We restricted our analyses to the Holocene period ( $11.5 \mathrm{cal} \mathrm{ka}$ BP to present). Qinghai Lake $\left(36.7^{\circ} \mathrm{N}, 100.5^{\circ} \mathrm{E}, 3200 \mathrm{~m}\right.$ a.s.l.; lake area $4400 \mathrm{~km}^{2}$; modern $\mathrm{P}_{\mathrm{ann}} 312 \mathrm{~mm}$ (interpolated from meteorological station data); species turnover 1.35 standard deviation units (SD, i.e. length of gradient on the first axis of Detrended Canonical Correspondence Analysis)) is located in the monsoon fringe area on the north-east Tibetan Plateau and surrounded by alpine shrub and alpine meadow steppe. The pollen record has six accelerator mass spectrometry (AMS) ${ }^{14} \mathrm{C}$ dates (four of them in the Holocene). In total, 207 samples were counted representing a resolution of one sample per 55 years (Liu et al., 2002). Gonghai Lake $\left(38.9^{\circ} \mathrm{N}, 112.2^{\circ} \mathrm{E}, 1860 \mathrm{~m}\right.$ a.s.l.; lake area $0.36 \mathrm{~km}^{2}$; modern $\mathrm{P}_{\mathrm{ann}}$ $505 \mathrm{~mm}$; species turnover: $1.48 \mathrm{SD}$ ) is located in the warmtemperate deciduous/broad-leaved forest zone in north-central China. The chronology of this pollen record is based on a combination of ${ }^{210} \mathrm{~Pb} /{ }^{137} \mathrm{Cs}$ dating and twenty-five AMS ${ }^{14} \mathrm{C}$ dates of terrestrial plant macrofossils. In total, there are 652 pollen samples in the Holocene interval, i.e. a temporal resolution of about 1 sample per 17 years (Chen et al., 2015). Sihailongwan Lake $\left(42.3^{\circ} \mathrm{N}, 126.6^{\circ} \mathrm{E}, 797 \mathrm{~m}\right.$ a.s.l.; lake area $0.4 \mathrm{~km}^{2}$; modern $P_{\text {ann }} 813 \mathrm{~mm}$; species turnover $1.25 \mathrm{SD}$ ) is located in the temperate coniferous and broad-leaved mixed forest in northeast China. The age-depth model is based on varve counting and forty AMS ${ }^{14} \mathrm{C}$ dates. In total, 191 pollen samples were analysed yielding a resolution of about 59 years per sample (Stebich et al., 2015). Both Qinghai Lake and Gonghai Lake are located in the marginal area of the East Asian Summer Monsoon, and their pollen spectra are presumed to be dominated by past precipitation changes. At Sihailongwan Lake (Stebich et al., 2015), however, temperature change might also be important, which could reduce the reliability of any precipitation reconstruction (Rehfeld et al., 2016).

\subsection{Numerical methods}

Geographic distance (great circle distance; km) between each modern sample site and each fossil site was calculated using the rdist.earth function in the fields package version 6.8 (Furrer et al., 2013) for R (R Core Team, 2012) based on their longitude/latitude coordinates. To explore the impact of the spatial extent of the calibration-set on model performance, analogue quality and $\mathrm{P}_{\text {ann }}$ reconstruction, circular calibration-sets were established using all available sites within a series of radii $(400,600,800,1000,1200$, $1500,2000,3000 \mathrm{~km}$ ) around each fossil site.

To demonstrate that the impact of spatial extent on the reconstruction was not biased by the variable number of sites, these analyses were also run with a standardised number of sites (randomly selected using the sample function) (see Appendix 1).

Furthermore, we investigated the differences in reconstructions based on calibration-sets located at different distances from the target fossil site, i.e. annular areas between 400 and $600 \mathrm{~km}, 600$ and $800 \mathrm{~km}, 800$ and $1000 \mathrm{~km}, 1000$ and $1200 \mathrm{~km}, 1200$ and $1500 \mathrm{~km}, 1500$ and $2000 \mathrm{~km}, 2000$ and $3000 \mathrm{~km}$ (see Appendix 1).

The $\mathrm{P}_{\text {ann }}$ reconstructions were made using the calibration-sets described above using WA-PLS and MAT in the rioja package version 0.7-3 (Juggins, 2012) for $\mathrm{R}$ with leave-one-out cross-validation. For WA-PLS, pollen percentages were square-root transformed to stabilise variances and optimise the signal-to-noise ratio (Prentice, 1980). For MAT, the original pollen percentages were used. The number of WA-PLS components was selected using a randomisation $t$-test (Juggins and Birks, 2012). In MAT, the squaredchord distance metric was used to measure the dissimilarity among pollen assemblages, and the weighted mean of climate data from five modern analogues (a model with five analogues has the best performance with our modern pollen dataset, see Cao et al., 2014) was calculated to represent the reconstruction. A statistical significance test for all reconstructions was performed following the 
methods described in Telford and Birks (2011) using the randomTF function in the palaeoSig package version 1.1.2 with WA-PLS and MAT as the reconstruction methods separately (Telford, 2013).

The taxonomic distance from fossil pollen assemblage to modern pollen assemblage is a common diagnostic for evaluating analogue quality. A distance shorter than the 5 th percentile of all distances between calibration-set assemblages is commonly used as a threshold for good analogues, while a distance above than the 10th percentile is assumed to signify a no-analogue assemblage: a moderate distance between the 10th and 5th percentile represents poor analogues (Birks et al., 1990). In this study, the squared chord distance between each fossil pollen assemblage and each modern pollen assemblage was calculated with the MAT function in the rioja package version 0.7-3 (Juggins, 2012). The distances between all modern assemblages (the squared chord distance) were calculated using the paldist function in rioja 0.7-3 (Juggins, 2012). The median of distances between each fossil pollen assemblage and its closest ten modern analogues was calculated and compared with the 10th and 5th percentile of all distances among all modern pollen assemblages to assess the analogue quality.

Local polynomial regression fitting (LOESS) and Huisman-OlffFresco (HOF; Huisman et al., 1993) modelling were employed to smooth the $P_{a n n}$ reconstructions and explore their general trends. HOF models are a hierarchical set of five response models with increasing complexity, including no response, monotonously increasing and decreasing, and symmetric and asymmetric unimodal responses. LOESS curves were fitted using the loess function in $\mathrm{R}$ with span at 0.25 ; HOF models were achieved using the gravy package version $0.2-0$ (Oksanen, 2013) for $R$ with a binomial error structure.

\section{Results}

\subsection{Effect of spatial extent of calibration-set on pollen-climate} model performance

For each test site, the series of circular calibration-sets with increasing spatial extent show a similar pattern in their model performances: the values of $\mathrm{r}^{2}$ and RMSEP generally increase while the RMSEP as a percentage of the modern gradient range (RMSEP\%) decreases for both WA-PLS (including component 1 and 2) and MAT (Table 1). The model performances and $P_{a n n}$ reconstructions using calibration-sets with a standardised number of sites are similar to those of the circular calibration-sets of corresponding spatial extent for each of the three pollen records (see Appendix 1) and are excluded from the description below. Detailed comparisons of the model performances yield slight differences among the three series of circular calibration-sets. For Qinghai Lake, notable increases in $r^{2}$ (from 0.73 to 0.78 for WAPLS comp-1; from 0.76 to 0.82 for WA-PLS comp-2; from 0.83 to 0.88 for MAT) and decreases in RMSEP\% (from $11.7 \%$ to $9.6 \%$ for WA-PLS comp-1; from $11.1 \%$ to $8.8 \%$ for WA-PLS comp-2; from $9.4 \%$ to $7.1 \%$ for MAT) occur when the radius of the calibration-set expands from 1000 to $1200 \mathrm{~km}$ (Table 1). All of the indicators imply that the calibration-set with a $1200 \mathrm{~km}$ spatial extent provides the best model performance. For Gonghai Lake, the models with the best performance are those with a spatial extent of $1000 \mathrm{~km}$ as they have high $\mathrm{r}^{2}(0.72,0.80$ and 0.82$)$, low RMSEP (137, 115 and $108 \mathrm{~mm}$ ) and low RMSEP\% (10.4\%, 8.8\% and 8.3\%), respectively for WA-PLS comp-1, WA-PLS comp-2, and MAT (Table 1). For Sihailongwan Lake, the $800-\mathrm{km}$ calibration-set yields the models with the best performance $\left(r^{2} 0.68,0.74\right.$ and 0.75; RMSEP 90, 81 and $79 \mathrm{~mm}$ ).

Annular calibration-sets possess higher $r^{2}$ than circular calibration-sets of the same spatial extent. Annular calibration-sets with large spatial extents (between 1500 and 2000 km, 2000 and $3000 \mathrm{~km}$ ) generally have a higher RMSEP than circular calibrationsets, which causes RMSEP\% to increase from the lower values found for the annular calibration-sets with moderate spatial extents (Appendix 1).

When using WA-PLS as a reconstruction method (both component 1 and 2), circular calibration-sets with spatial extents $\geq 1000 \mathrm{~km}$ pass the statistical significance test $(p \leq 0.05)$ for the three sites, while the circular calibration-sets with smaller spatial extent fail. With MAT, all of the circular calibration-sets for Gonghai Lake pass the statistical significance test regardless of spatial

Table 1

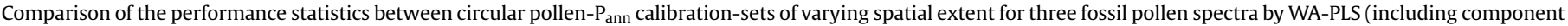
1 and 2) and MAT (indices presented in the Table are listed as WA-PLS-component-1/2 (MAT)). SHLW=Sihailongwan.

\begin{tabular}{|c|c|c|c|c|c|c|c|c|}
\hline Record & Calibration-set radius (km) & Number of sites & $\mathrm{P}_{\mathrm{ann}}$ gradient $(\mathrm{mm})$ & Selected comp. & $\mathrm{r}^{2}$ & RMSEP (mm) & RMSEP \% of grad & Significance \\
\hline \multirow[t]{8}{*}{ Qinghai Lake } & 400 & 418 & $67-774$ & 1 & $0.59 / 0.61(0.72)$ & $101 / 99(84)$ & $14.3 / 14.0(11.9)$ & $0.68 / 0.06(0.23)$ \\
\hline & 600 & 596 & $35-822$ & 1 & $0.68 / 0.70(0.81)$ & $114 / 111(88)$ & $14.5 / 14.1(11.2)$ & $0.24 / 0.15(0.58)$ \\
\hline & 800 & 750 & $35-1082$ & 1 & $0.74 / 0.76(0.84)$ & $122 / 117(95)$ & $11.7 / 11.2(9.1)$ & $0.03 / 0.01(0.54)$ \\
\hline & 1000 & 896 & $35-1082$ & 1 & $0.73 / 0.76(0.83)$ & $122 / 117(98)$ & $11.7 / 11.1(9.4)$ & $0.03 / 0.01(0.52)$ \\
\hline & 1200 & 1198 & $35-1349$ & 2 & $0.78 / 0.82(0.88)$ & $127 / 115(93)$ & $9.6 / 8.8(7.1)$ & $0.01 / 0.01(0.41)$ \\
\hline & 1500 & 1706 & $35-1503$ & 2 & $0.76 / 0.79(0.88)$ & $136 / 128(98)$ & $9.3 / 8.7(6.7)$ & $0.01 / 0.01(0.32)$ \\
\hline & 2000 & 2209 & $35-2241$ & 2 & $0.84 / 0.86(0.91)$ & $183 / 171(135)$ & $8.3 / 7.8(6.1)$ & $0.01 / 0.01(0.36)$ \\
\hline & 3000 & 2761 & $14-2240$ & 2 & $0.85 / 0.87(0.94)$ & $212 / 198(140)$ & $9.5 / 8.9(6.3)$ & $0.02 / 0.01(0.53)$ \\
\hline \multirow[t]{8}{*}{ Gonghai Lake } & 400 & 164 & $213-654$ & 1 & $0.55 / 0.61(0.62)$ & $79 / 75$ (74) & $18.0 / 17.0(16.7)$ & $0.01 / 0.01(0.05)$ \\
\hline & 600 & 408 & $144-710$ & 1 & $0.54 / 0.59(0.59)$ & $104 / 98(100)$ & $18.4 / 17.3(17.6)$ & $0.01 / 0.08(0.01)$ \\
\hline & 800 & 548 & $97-1082$ & 1 & $0.65 / 0.70(0.73)$ & $122 / 114(108)$ & $12.4 / 11.6(11.0)$ & $0.01 / 0.01(0.01)$ \\
\hline & 1000 & 769 & $41-1349$ & 2 & $0.72 / 0.80(0.82)$ & $137 / 115(108)$ & $10.4 / 8.8(8.3)$ & $0.01 / 0.01(0.01)$ \\
\hline & 1200 & 1086 & $35-1755$ & 2 & $0.73 / 0.78(0.83)$ & $157 / 141(122)$ & $9.1 / 8.2(7.1)$ & $0.01 / 0.01(0.01)$ \\
\hline & 1500 & 1535 & $35-2241$ & 2 & $0.79 / 0.83(0.88)$ & $162 / 146(121)$ & $7.4 / 6.6(5.5)$ & $0.01 / 0.01(0.02)$ \\
\hline & 2000 & 2281 & $35-2241$ & 2 & $0.85 / 0.87(0.93)$ & $211 / 197$ (143) & $9.6 / 8.9(6.5)$ & $0.01 / 0.01(0.01)$ \\
\hline & 3000 & 2723 & $35-2214$ & 2 & $0.85 / 0.87(0.93)$ & $212 / 197$ (141) & $9.6 / 9.0(6.4)$ & $0.01 / 0.01(0.01)$ \\
\hline \multirow[t]{8}{*}{ SHLW Lake } & 400 & 42 & 407-1006 & 1 & $0.66 / 0.64(0.70)$ & 103/106 (99) & $17.1 / 17.7(16.5)$ & $0.49 / 0.82(0.44)$ \\
\hline & 600 & 57 & $365-1006$ & 1 & $0.70 / 0.68(0.76)$ & $99 / 104(90)$ & $15.4 / 16.3(14.0)$ & $0.37 / 0.70(0.45)$ \\
\hline & 800 & 148 & $365-1006$ & 2 & $0.68 / 0.74(0.75)$ & $90 / 81(79)$ & $14.1 / 12.7(12.3)$ & $0.07 / 0.15(0.21)$ \\
\hline & 1000 & 412 & 226-1006 & 1 & $0.56 / 0.62(0.71)$ & $95 / 89(78)$ & $12.2 / 11.4(10.0)$ & $0.02 / 0.02(0.45)$ \\
\hline & 1200 & 583 & $151-1006$ & 2 & $0.56 / 0.64(0.67)$ & $108 / 97(94)$ & $12.6 / 11.3(11.0)$ & $0.01 / 0.02(0.40)$ \\
\hline & 1500 & 694 & $112-1755$ & 1 & $0.73 / 0.75(0.82)$ & $134 / 129(113)$ & $8.1 / 7.8(6.9)$ & $0.02 / 0.02(0.39)$ \\
\hline & 2000 & 959 & $52-2241$ & 2 & $0.73 / 0.78(0.84)$ & $176 / 158(138)$ & $8.0 / 7.2(6.3)$ & $0.02 / 0.01(0.39)$ \\
\hline & 3000 & 2243 & $35-2241$ & 1 & $0.85 / 0.87(0.93)$ & $215 / 199$ (145) & $9.7 / 9.0(6.6)$ & $0.08 / 0.05(0.31)$ \\
\hline
\end{tabular}


extent; while the other two sites all fail (Table 1).

\subsection{Effect of spatial extent of calibration-set on analogue quality}

Training-sets for Qinghai Lake and Gonghai Lake indicate that the analogue quality is improved when calibration-sets expand from small sizes $(<800 \mathrm{~km})$ to intermediate sizes (ca. $1500 \mathrm{~km})$. Further expansions do not improve analogue quality markedly but the heterogeneity of the calibration-sets deteriorates (Fig. 2A and B; Appendix 1). For Gonghai Lake, fossil pollen assemblages before 6 cal ka BP have higher dissimilarities with their modern analogues than the assemblages younger than 6 cal ka BP. When using calibration-sets of increasing spatial extent, more and more fossil pollen assemblages have analogues, particularly when the radius extends beyond $1500 \mathrm{~km}$. However, the 10th and 5th percentiles rise, particularly beyond $2000 \mathrm{~km}$ (Fig. 2B). Tests of annular calibration-sets reveal that a calibration-set between 1200 and $1500 \mathrm{~km}$ has the closest analogues, particularly for fossil pollen assemblages before $6 \mathrm{cal}$ ka BP (Appendix 1). Unlike Gonghai Lake, almost all fossil pollen assemblages from Qinghai Lake have analogues (good and poor) in all circular calibrationsets, and the analogue quality improves slightly when the radii of the trainings-sets increase (Fig. 2A); the closest analogues are found at distances ranging between 1200 and $2000 \mathrm{~km}$ (Appendix 1).

For Sihailongwan Lake pollen spectra, fossil pollen assemblages younger than ca. 3 cal ka BP possess poor analogues, while older assemblages cannot find analogues from any of the calibration-sets. The closest "analogues" are located within a 400-km radius around the lake, and their distances to fossil pollen assemblages do not reduce when the spatial extent of the calibration-set is expanded (Fig. 2C; Appendix 1).

\subsection{Effect of the spatial extent of the calibration-set on climate reconstruction}

For all three sites, $\mathrm{P}_{\mathrm{ann}}$ reconstructions with circular calibrationsets of different spatial extent notably differ in absolute values, range, trend and optimum irrespective of the reconstruction method applied (WA-PLS or MAT). The differences are generally larger for MAT than for WA-PLS.

With respect to WA-PLS, the absolute value of recent $\mathrm{P}_{\mathrm{ann}}$ reconstructions (represented by the mean reconstructed $\mathrm{P}_{\mathrm{ann}}$ over the last two centuries; Table 2) for Qinghai Lake are consistent with the modern $P_{\text {ann }}$ for all circular calibration-sets, while the absolute values are underestimated to some extent for Sihailongwan Lake and Gonghai Lake, with the degree of underestimation being related to the spatial extent of the calibration-set. For example, the underestimation is particularly large when using large calibrationsets (2000 and $3000 \mathrm{~km}$ ) for Gonghai Lake and for Sihailongwan Lake (Table 2).

For all sites, the ranges of $\mathrm{P}_{\mathrm{ann}}$ reconstructions increase with the spatial extent of the circular calibration-sets. For example, the $\mathrm{P}_{\mathrm{ann}}$ range increases from $64 \mathrm{~mm}$ inferred from the $400-\mathrm{km}$ set to $300 \mathrm{~mm}$ with the $3000-\mathrm{km}$ set for Gonghai Lake (Table 2).

Except for the monotonously decreasing $\mathrm{P}_{\mathrm{ann}}$ trend revealed by the $400-\mathrm{km}$ set for Qinghai Lake, all other circular calibrationsets yield a unimodal temporal pattern for the three study sites when using WA-PLS (Fig. 3A). However, the timing of the $\mathrm{P}_{\mathrm{ann}}$ optima differs markedly with the spatial extent of the calibrationsets (Fig. 3A). The $P_{a n n}$ optima for Gonghai Lake and Sihailongwan Lake are located between ca. 6.4-7.6 cal ka BP when inferred from small and intermediate-sized calibration-sets ( $\leq 1500 \mathrm{~km}$ radius); while their optima shift to 3.4 and 4.2 cal ka BP, respectively, when the spatial extent is 2000 and $3000 \mathrm{~km}$, respectively; this optima shift is also seen in the annular calibration-sets (Appendix 1). $P_{a n n}$ optima for Qinghai Lake are located around 8.4 cal ka BP when inferred by intermediate and large-scale circular calibration-sets, while the optimum is at 0 cal ka BP with the 400km set (Fig. 3A).

With respect to MAT, the underestimations in the absolute values of reconstructed $\mathrm{P}_{\mathrm{ann}}$ also deteriorate with spatial extent of the calibration-set, and to a greater degree than WA-PLS for Qinghai Lake and Gonghai Lake. The differences in $\mathrm{P}_{\mathrm{ann}}$ reconstructions are even larger than those revealed by WA-PLS for the different calibration-sets. For example, calibration-sets of varying spatial extent (both circular and annular calibration-sets) show reverse temporal trends (for Qinghai Lake), and produce unstable optima for Gonghai Lake. Compared with the other two sites, the $\mathrm{P}_{\mathrm{ann}}$ reconstructions for the Sihailongwan Lake only show minor changes when the spatial extent of the calibration-set increases (Table 2; Fig. 3B; Appendix 1).

\section{Discussion}

\subsection{Influence of spatial extent of calibration-set on model performance, analogue quality and $P_{\text {ann }}$ reconstruction}

Our analyses show that calibration model performance, analogue quality and quantitative climate reconstruction diagnostics (including absolute value, range, trend and optimum) for a target site strongly depend on the spatial extent of the modern pollen calibration-set.

A dependence of $r^{2}$ and RMSEP as inferred from the "leave-oneout" cross-validation between observed and predicted climate variable values on the spatial extent of the modern pollen calibration-set was discussed in previous studies (Birks, 1998), but not systematically investigated. These measures are traditionally used to assess model performance. However, our results indicate that their absolute values have only limited value as indicators of model performance as they typically increase with spatial extent of the calibration-set. Still, our results suggest that $r^{2}$ and RMSEP when calculated across a range of spatial extents may represent useful measures for the selection of the best suited calibration-set. Previous studies additionally used the RMSEP as a percentage of the climatic gradient range of the calibration-set (e.g. Finsinger et al., 2007; Herzschuh et al., 2010) to compare model performances of several calibration-sets with different climate-gradient lengths: a method our results support.

The inclusion of high-quality modern analogues of the fossil pollen assemblages in the calibration-set increases the reliability of reconstruction for both regression-based approaches (e.g. WAPLS) and analogue-based approaches (e.g. MAT) (Birks et al., 1990). A spatially larger calibration-set typically increases the analogue quality as the analogues originate from a wider variety of vegetation conditions, as seen for Qinghai Lake and Gonghai Lake where the closest analogues are selected from distances ranging between 1200 and $2000 \mathrm{~km}$ and 1200 and $1500 \mathrm{~km}$, respectively (Appendix 1). For Sihailongwan Lake though, the closest "analogues" are located within $400 \mathrm{~km}$ around the lake (Appendix 1). The spatially extended calibration-set does not improve analogue quality, particularly for samples in the earlyand mid-Holocene (Fig. 2C), which may be caused by the sparsity of available modern sites around the lake and the different seasonality pattern of the insolation-driven monsoon at these times (Zhu et al., 2013; Kong et al., 2017). When extending the calibration-set, the taxonomic resolution of pollen data effectively decreases, because the number of species contributing to each pollen morphotype increases. Further it raises the risk of inappropriate matches between analogue and fossil pollen samples 

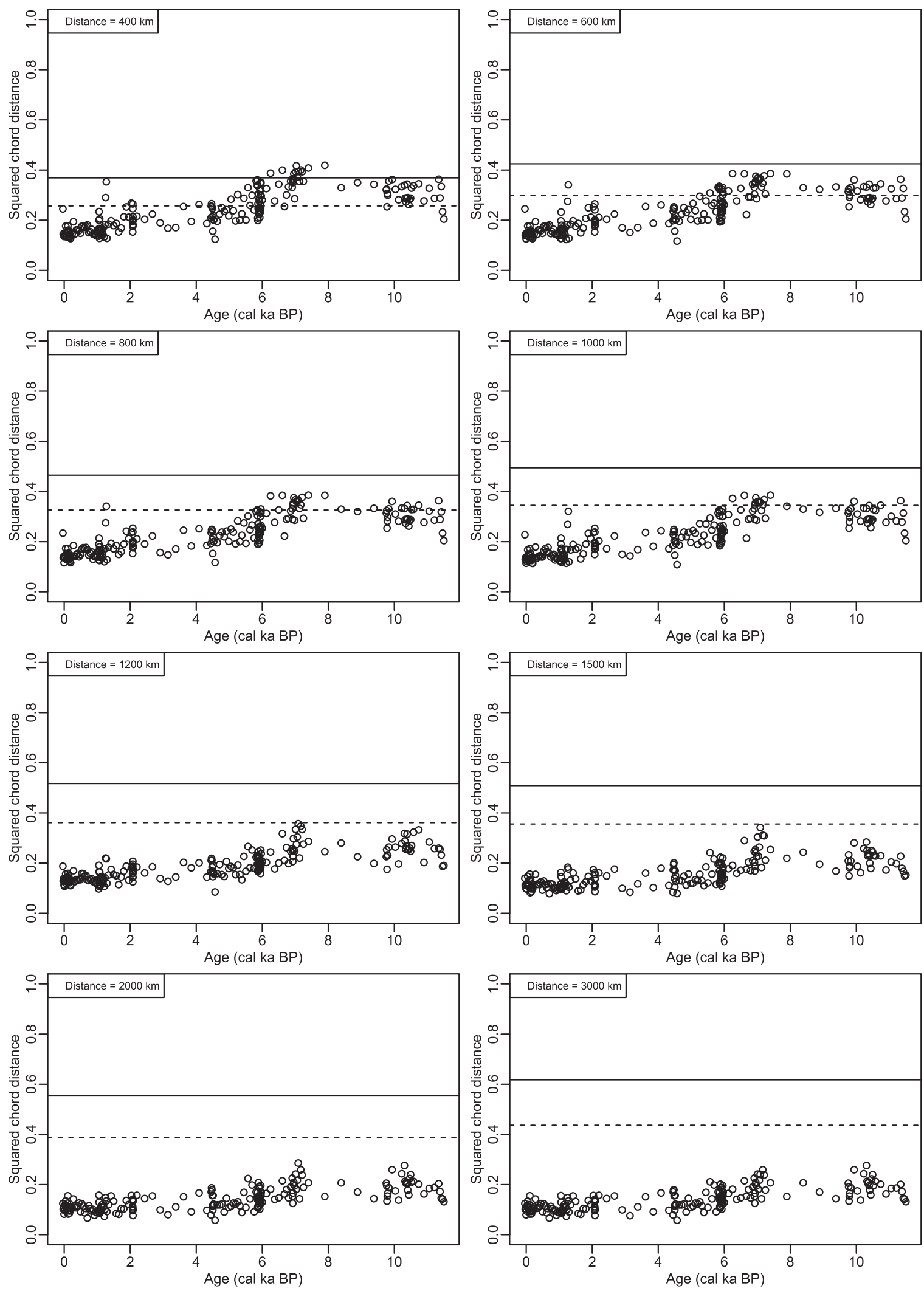

A

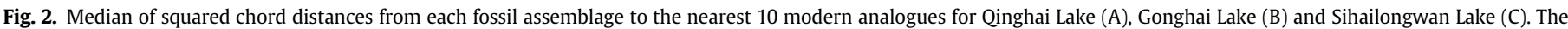
dashed and solid horizontal lines indicate the 5th and 10th percentiles of all distances between calibration-set pollen assemblages, respectively. 

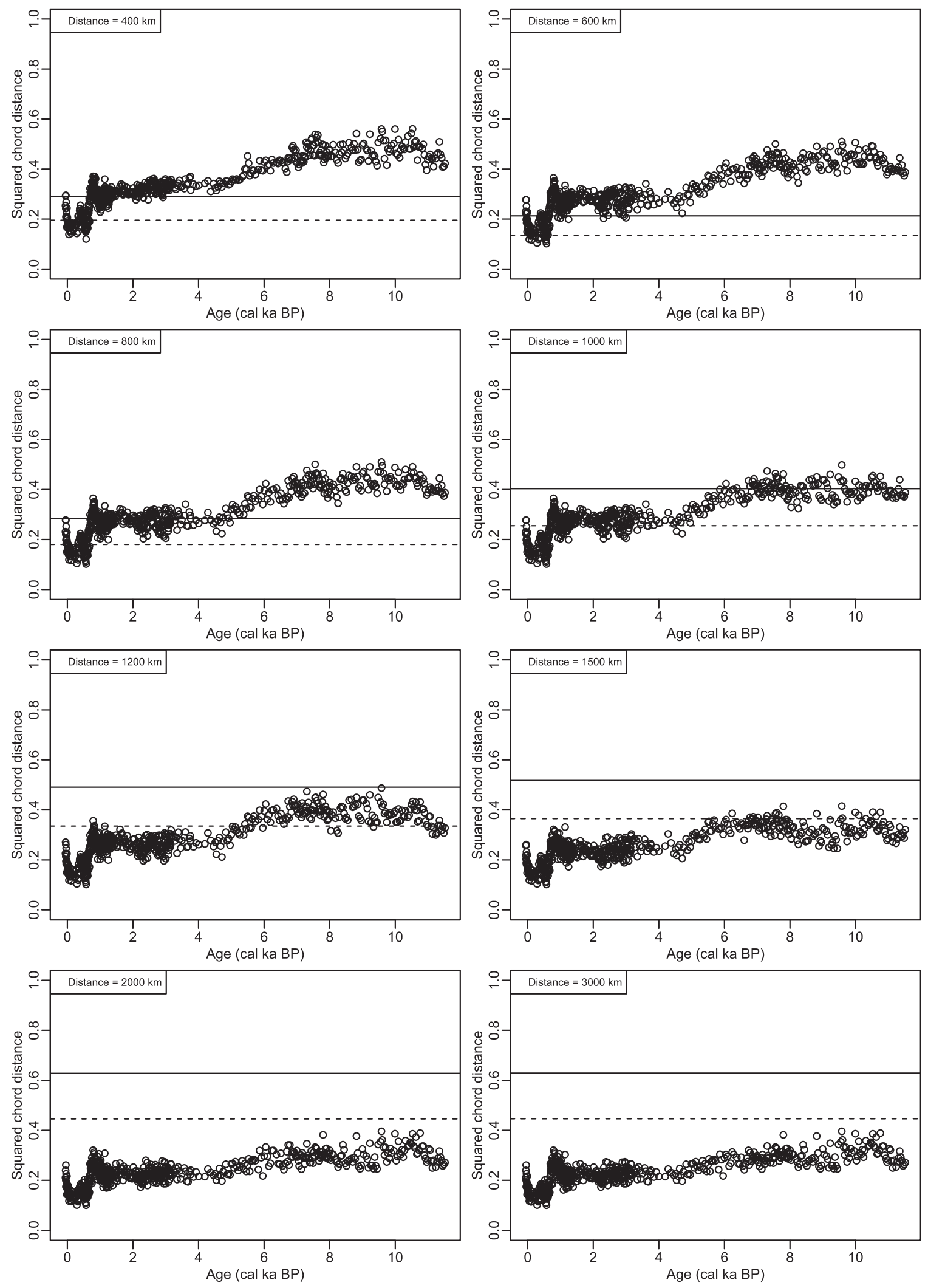

B

Fig. 2. (continued). 

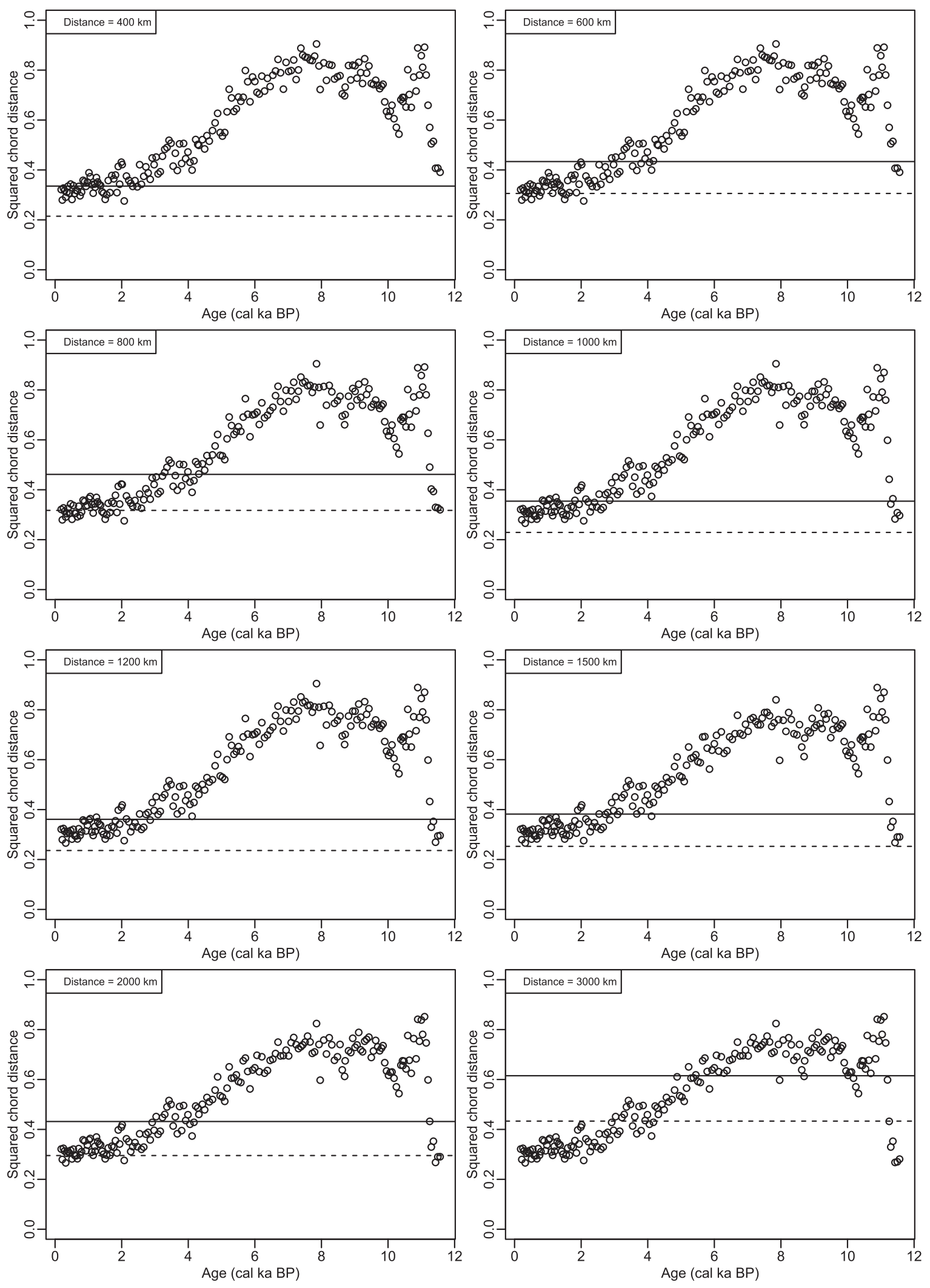

C

Fig. 2. (continued). 
Table 2

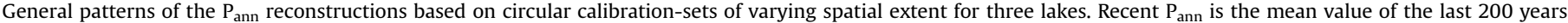

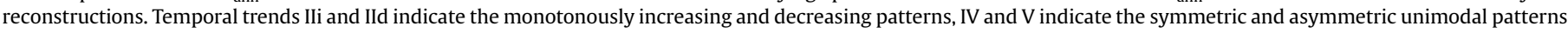

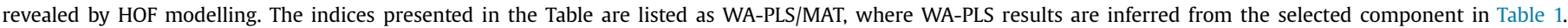
$\mathrm{SHLW}=$ Sihailongwan.

\begin{tabular}{|c|c|c|c|c|c|c|c|c|c|}
\hline \multirow[t]{2}{*}{ Lake (modern $\mathrm{P}_{\mathrm{ann}}$ ) } & \multirow[b]{2}{*}{ Radius (km) } & \multicolumn{8}{|c|}{ WA-PLS/MAT } \\
\hline & & 400 & 600 & 800 & 1000 & 1200 & 1500 & 2000 & 3000 \\
\hline \multirow{6}{*}{$\begin{array}{l}\text { Qinghai Lake } \\
\text { (312 mm) }\end{array}$} & \multirow{6}{*}{$\begin{array}{l}\text { Recent } \mathrm{P}_{\mathrm{ann}} \\
\text { trend } \\
\text { optimum } \\
\text { minimum } \\
\text { maximum } \\
\text { range }\end{array}$} & $364 / 332$ & $343 / 328$ & $331 / 322$ & $340 / 295$ & $327 / 303$ & $326 / 278$ & $324 / 269$ & $311 / 247$ \\
\hline & & IId/IId & $\mathrm{V} / \mathrm{V}$ & $\mathrm{V} / \mathrm{V}$ & $\mathrm{V} / \mathrm{V}$ & $\mathrm{V} / \mathrm{V}$ & $\mathrm{V} / \mathrm{Ili}$ & $\mathrm{V} / \mathrm{IIi}$ & $\mathrm{V} / \mathrm{IIi}$ \\
\hline & & $0 / 9.8$ & $8.9 / 7.9$ & $8.4 / 7.9$ & $8.4 / 7.9$ & $8.4 / 7.4$ & $7.9 / 2.9$ & $8.4 / 2.9$ & $8.4 / 2.9$ \\
\hline & & $337 / 302$ & $330 / 314$ & $319 / 308$ & $329 / 289$ & $312 / 280$ & $310 / 202$ & $311 / 167$ & $295 / 166$ \\
\hline & & $395 / 408$ & $416 / 491$ & $465 / 493$ & $479 / 503$ & $453 / 429$ & $464 / 312$ & $500 / 299$ & $529 / 299$ \\
\hline & & $58 / 106$ & $86 / 177$ & $146 / 185$ & $150 / 214$ & $141 / 149$ & $154 / 110$ & $189 / 132$ & $234 / 133$ \\
\hline \multirow{6}{*}{$\begin{array}{l}\text { Gonghai Lake } \\
\text { (505 mm) }\end{array}$} & \multirow{6}{*}{$\begin{array}{l}\text { Recent } \mathrm{P}_{\mathrm{ann}} \\
\text { trend } \\
\text { optimum } \\
\text { minimum } \\
\text { maximum } \\
\text { range }\end{array}$} & $481 / 386$ & $454 / 361$ & $438 / 361$ & $450 / 361$ & $445 / 376$ & $426 / 347$ & $395 / 312$ & $376 / 311$ \\
\hline & & $\mathrm{V} / \mathrm{V}$ & $\mathrm{V} / \mathrm{V}$ & $\mathrm{V} / \mathrm{V}$ & $\mathrm{V} / \mathrm{V}$ & $\mathrm{V} / \mathrm{V}$ & $\mathrm{V} / \mathrm{V}$ & $\mathrm{V} / \mathrm{V}$ & $\mathrm{V} / \mathrm{V}$ \\
\hline & & $7.0 / 1.9$ & $6.4 / 6.0$ & $6.5 / 6.2$ & $6.5 / 6.3$ & $6.5 / 6.2$ & $6.6 / 9.1$ & $3.4 / 9.2$ & $3.4 / 9.2$ \\
\hline & & $464 / 369$ & $438 / 351$ & $423 / 350$ & $435 / 350$ & $430 / 366$ & $406 / 338$ & $370 / 260$ & $352 / 238$ \\
\hline & & $592 / 593$ & $561 / 641$ & $582 / 649$ & $613 / 654$ & $655 / 650$ & $650 / 728$ & $626 / 707$ & $626 / 707$ \\
\hline & & $128 / 224$ & $123 / 290$ & $159 / 299$ & $178 / 304$ & $225 / 284$ & $244 / 390$ & $256 / 447$ & $274 / 469$ \\
\hline \multirow{6}{*}{$\begin{array}{l}\text { SHLW Lake } \\
(813 \mathrm{~mm})\end{array}$} & \multirow{6}{*}{$\begin{array}{l}\text { Recent } P_{\text {ann }} \\
\text { trend } \\
\text { optimum } \\
\text { minimum } \\
\text { maximum } \\
\text { range }\end{array}$} & $718 / 673$ & $724 / 673$ & $718 / 673$ & $638 / 673$ & $638 / 673$ & $655 / 673$ & $674 / 673$ & $633 / 673$ \\
\hline & & IV/IV & $\mathrm{V} / \mathrm{IV}$ & $\mathrm{V} / \mathrm{V}$ & $\mathrm{V} / \mathrm{V}$ & $\mathrm{V} / \mathrm{V}$ & $\mathrm{V} / \mathrm{V}$ & $\mathrm{V} / \mathrm{V}$ & $\mathrm{V} / \mathrm{V}$ \\
\hline & & $7.2 / 7.2$ & $7.0 / 7.2$ & $6.9 / 8.0$ & $7.2 / 8.0$ & $7.2 / 8.0$ & 7.1/7.7 & $7.6 / 6.3$ & $4.2 / 6.3$ \\
\hline & & $712 / 656$ & $717 / 656$ & $654 / 592$ & $591 / 452$ & $560 / 446$ & $558 / 472$ & $568 / 474$ & $503 / 465$ \\
\hline & & $774 / 812$ & $790 / 812$ & $847 / 797$ & $765 / 797$ & $828 / 797$ & $804 / 792$ & $893 / 771$ & $803 / 771$ \\
\hline & & $62 / 156$ & $73 / 156$ & $193 / 205$ & $174 / 345$ & $268 / 351$ & $246 / 320$ & $325 / 297$ & $300 / 306$ \\
\hline
\end{tabular}

(Williams and Shuman, 2008). Our study reveals that analogue quality increases non-linearly with the spatial extent of the circular calibration-set and thus can guide the selection of the spatial extent of the calibration-set. For example, using a circular calibration-set with a very large spatial extent (e.g. 2000 or $3000 \mathrm{~km}$ ) does not improve analogue quality at Gonghai Lake over a 1500-km set (Fig. 2B; Appendix 1).

Our results (both WA-PLS and MAT) indicate that the absolute reconstructed $\mathrm{P}_{\mathrm{ann}}$ values depend on the spatial extent of the calibration-set. For example, compared with modern $\mathrm{P}_{\mathrm{ann}}$ $(813 \mathrm{~mm})$ at Sihailongwan Lake, the reconstructed $\mathrm{P}_{\text {ann }}$ underestimates recent conditions by up to $142 \mathrm{~mm}$ with circular calibration-sets of intermediate and large extents when using WA-PLS and by all circular calibration-sets using MAT (Fig. 3A and B). Sihailongwan Lake, located in north-east China, is characterised by high $\mathrm{P}_{\mathrm{ann}}$ despite being located outside the subtropical and tropical areas. The extension of the circular calibration-set from small $(<1000 \mathrm{~km})$ to intermediate $(1000-1500 \mathrm{~km})$ spatial extent allows the inclusion of more modern pollen samples from arid/semi-arid areas in north-central China and Mongolia, thus enhancing the underestimation of $\mathrm{P}_{\mathrm{ann}}$ with WA-PLS (Fig. 3A). However, increasing the radius of the calibration-set further to $2000 \mathrm{~km}$ produces higher reconstruction values (using WA-PLS), probably caused by the inclusion of moist sites from tropical areas in southern China. Most of the closed modern "analogues" for the fossil pollen spectra of Sihailongwan Lake are located in the relatively dry north-eastern and northern China, which thus causes the underestimations by MAT (Figs. 3B and 4C). In addition, the interpolated modern $\mathrm{P}_{\mathrm{ann}}(813 \mathrm{~mm})$ is higher than the modern observation of $775 \mathrm{~mm}$ (mean of annual precipitation between 1955 and 1997 of Jingyu meteorological station, ca. $20 \mathrm{~km}$ north-east from Sihailongwan Lake, see Schettler et al., 2006), and thus does not represent the $P_{a n n}$ condition of the pollen source area. This may explain the $P_{a n n}$ underestimation to some extent. Likewise, late-Holocene precipitation for Gonghai Lake is underestimated by circular calibration-sets, particularly the 2000- and 3000-km calibration-sets (for both methods; Fig. $3 \mathrm{~A}$ and $\mathrm{B}$ ). This might be caused by the inclusion of modern analogues mainly from north and west of the lake with low $\mathrm{P}_{\mathrm{ann}}$ into the calibration-sets (Fig. 4B). In contrast, all the $\mathrm{P}_{\text {ann }}$ reconstructions of Qinghai Lake using WA-PLS are generally consistent with the modern $P_{a n n}$ because the lake is located in the central range of the $P_{a n n}$ gradient and thus the change in spatial extent encompasses a relatively symmetrical addition of pollen sites on the $\mathrm{P}_{\mathrm{ann}}$ gradient. Despite the $\mathrm{P}_{\mathrm{ann}}$ underestimation for Sihailongwan Lake and Gonghai Lake, we still consider that the generally consistent $\mathrm{P}_{\mathrm{ann}}$ temporal patterns as revealed by our series of calibration-sets are reliable.

Our results further indicate that the range of reconstructed $P_{a n n}$ depends strongly on the selected spatial extent of the calibration-set (Fig. 3A and B). For example, the narrow $\mathrm{P}_{\text {ann }}$ range of $58 \mathrm{~mm}$ inferred for Qinghai Lake with the 400-km calibrationset using WA-PLS increases to $234 \mathrm{~mm}$ when using the $3000-\mathrm{km}$ calibration-set (Fig. $3 \mathrm{~A}$ and $\mathrm{B}$ ). The lowest $\mathrm{P}_{\mathrm{ann}}$ values are mostly inferred for the late Holocene, when the pollen spectra are dominated by non-arboreal taxa (e.g. Artemisia and Chenopodiaceae), while the highest $\mathrm{P}_{\mathrm{ann}}$ values are generally inferred for the middle Holocene when the spectra possess abundant arboreal taxa (e.g. Pinus and Quercus; Liu et al., 2002; Chen et al., 2015; Stebich et al., 2015). The spatial extension of a calibration-set implies that more modern pollen samples are added to both the arid and moist ends of the $P_{a n n}$ gradient, which shifts pollen taxa with a preference for wet conditions towards the wet-end (e.g. Pinus and Quercus) and drought-tolerant taxa (e.g. Artemisia and Chenopodiaceae) towards the dry-end, thus elongating the reconstructed $\mathrm{P}_{\text {ann }}$ ranges.

The temporal trends of $\mathrm{P}_{\mathrm{ann}}$ as reconstructed by the series of calibration-sets for the three sites using WA-PLS are rather similar (asymmetric or symmetric unimodal) (Fig. 3A), while the trends of the MAT-based reconstructions for Qinghai Lake and Gonghai Lake differ strongly (Fig. 3B). For Qinghai Lake a reversal of the overall Holocene trends is inferred, which likely originates from the presence of multiple analogues, i.e. similar modern biological assemblages with different environmental values (Birks et al., 2010). Annular calibration-sets results reveal that the closest modern analogues for the early- and mid-Holocene pollen spectra from Qinghai Lake occur in the range between 1200 and $2000 \mathrm{~km}$ (Appendix 1) and are located in west Mongolia (Fig. 4A), 

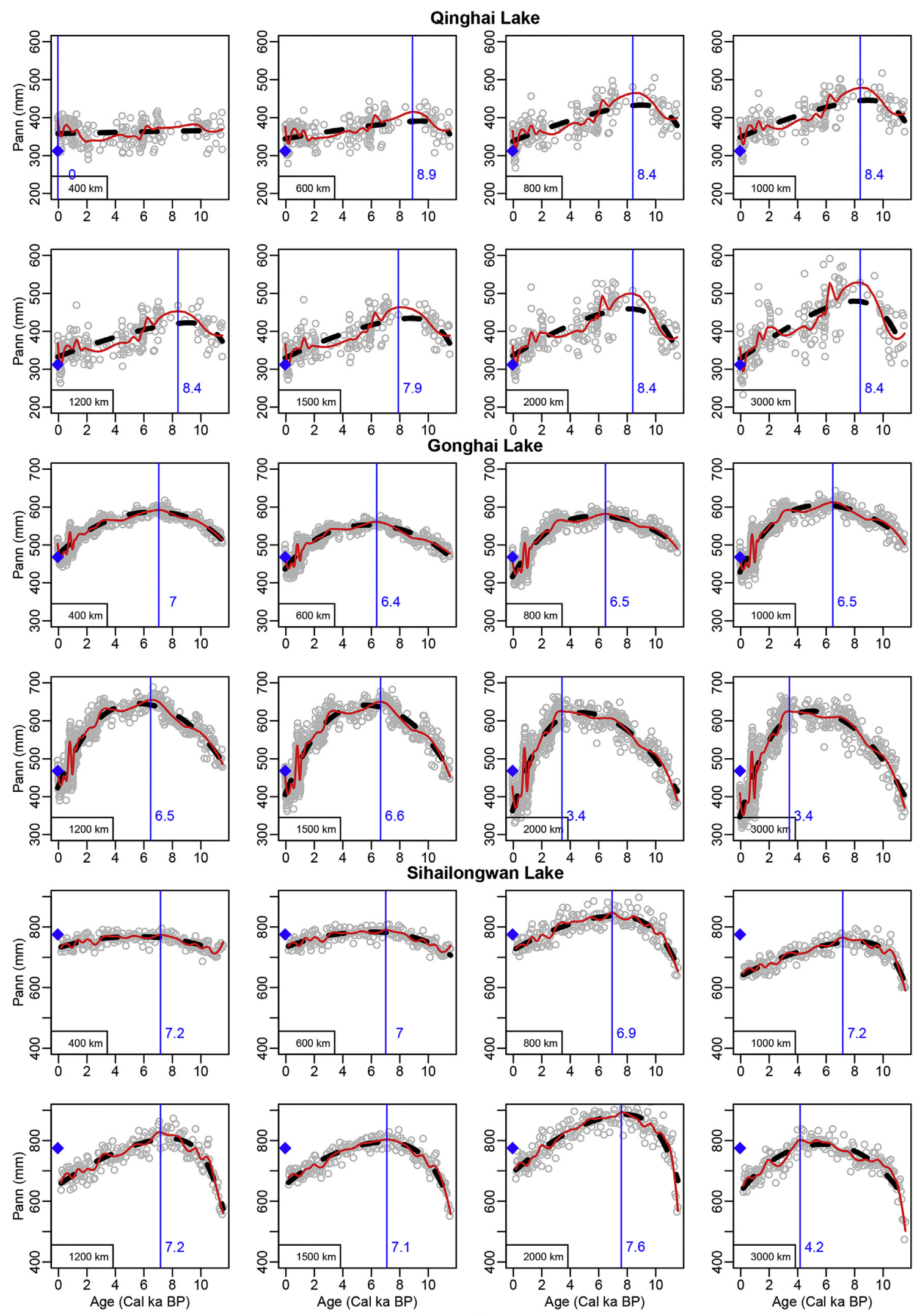

A

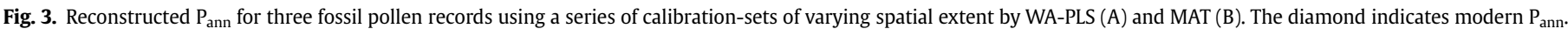

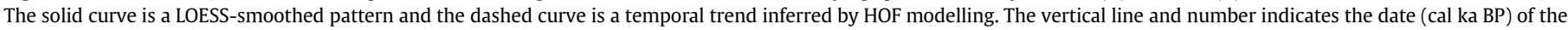
$\mathrm{P}_{\text {ann }}$ optimum. SHLW=Sihailongan. 

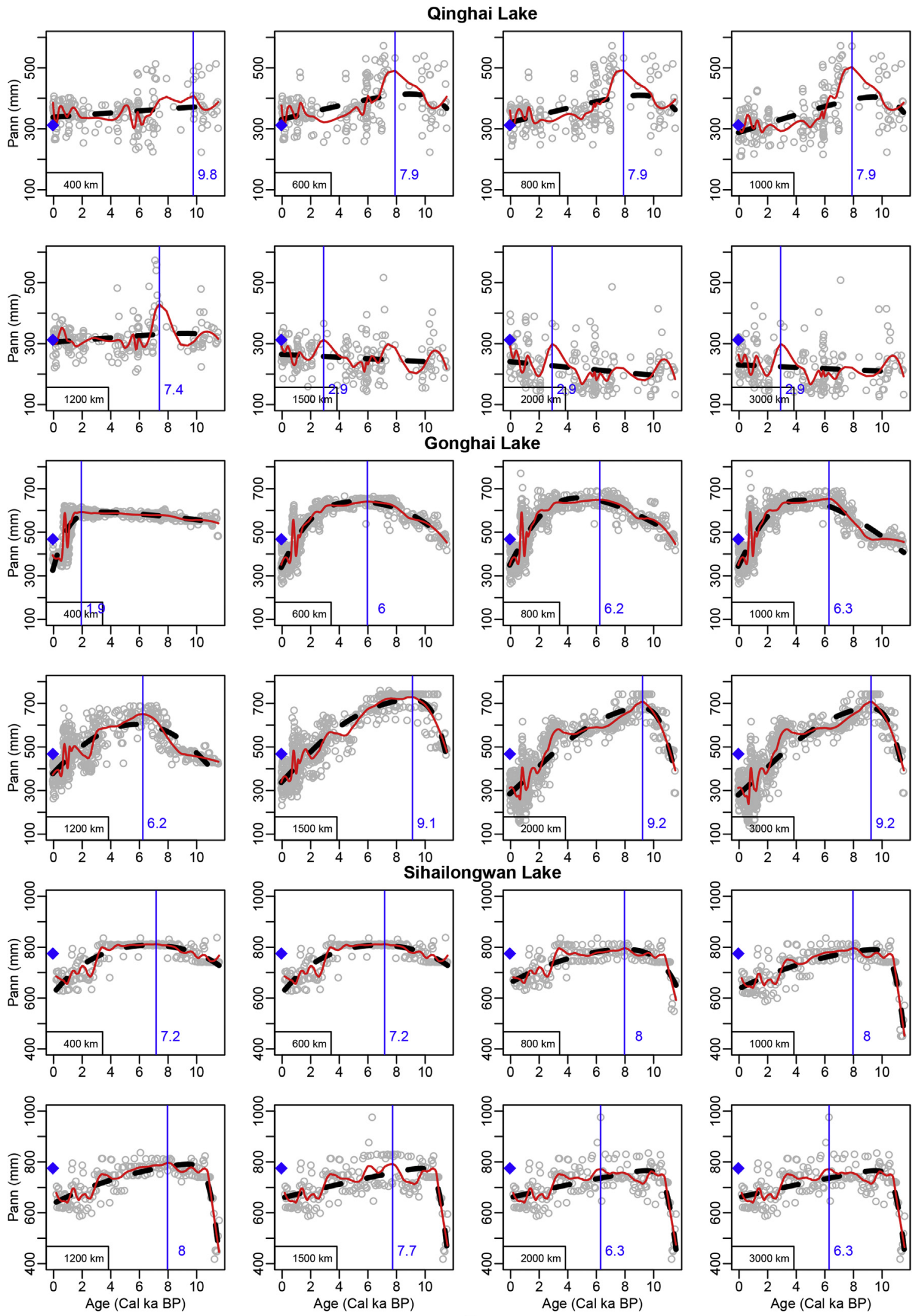

Fig. 3. (continued) 

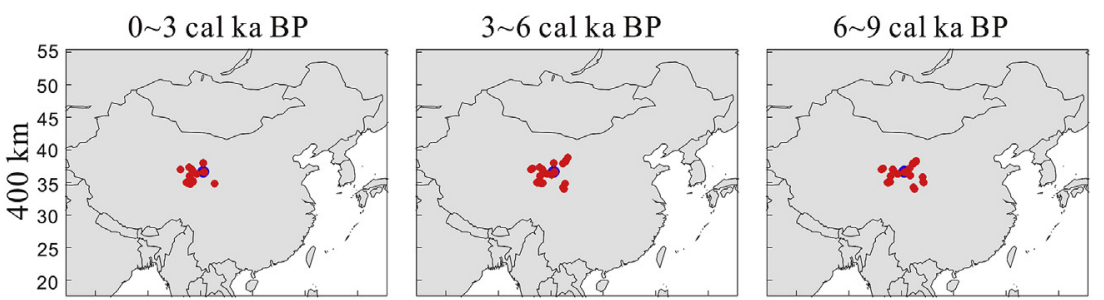

$9 \sim 11.5 \mathrm{cal} \mathrm{ka} \mathrm{BP}$
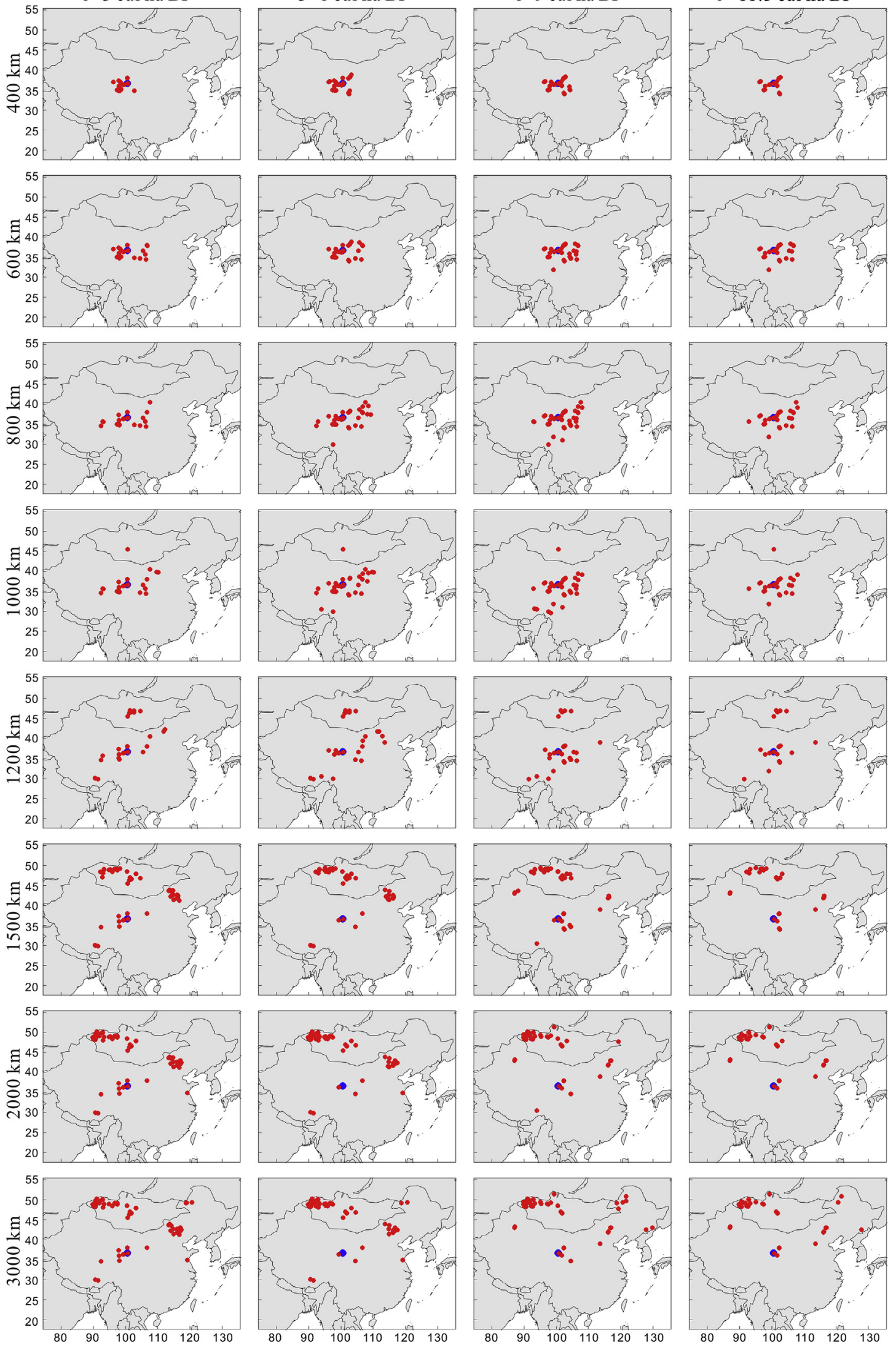

A

Fig. 4. Location of the modern analogues for the fossil pollen spectra from Qinghai Lake (A), Gonghai Lake (B) and Sihailongwan Lake (C) for selected time-slices. 

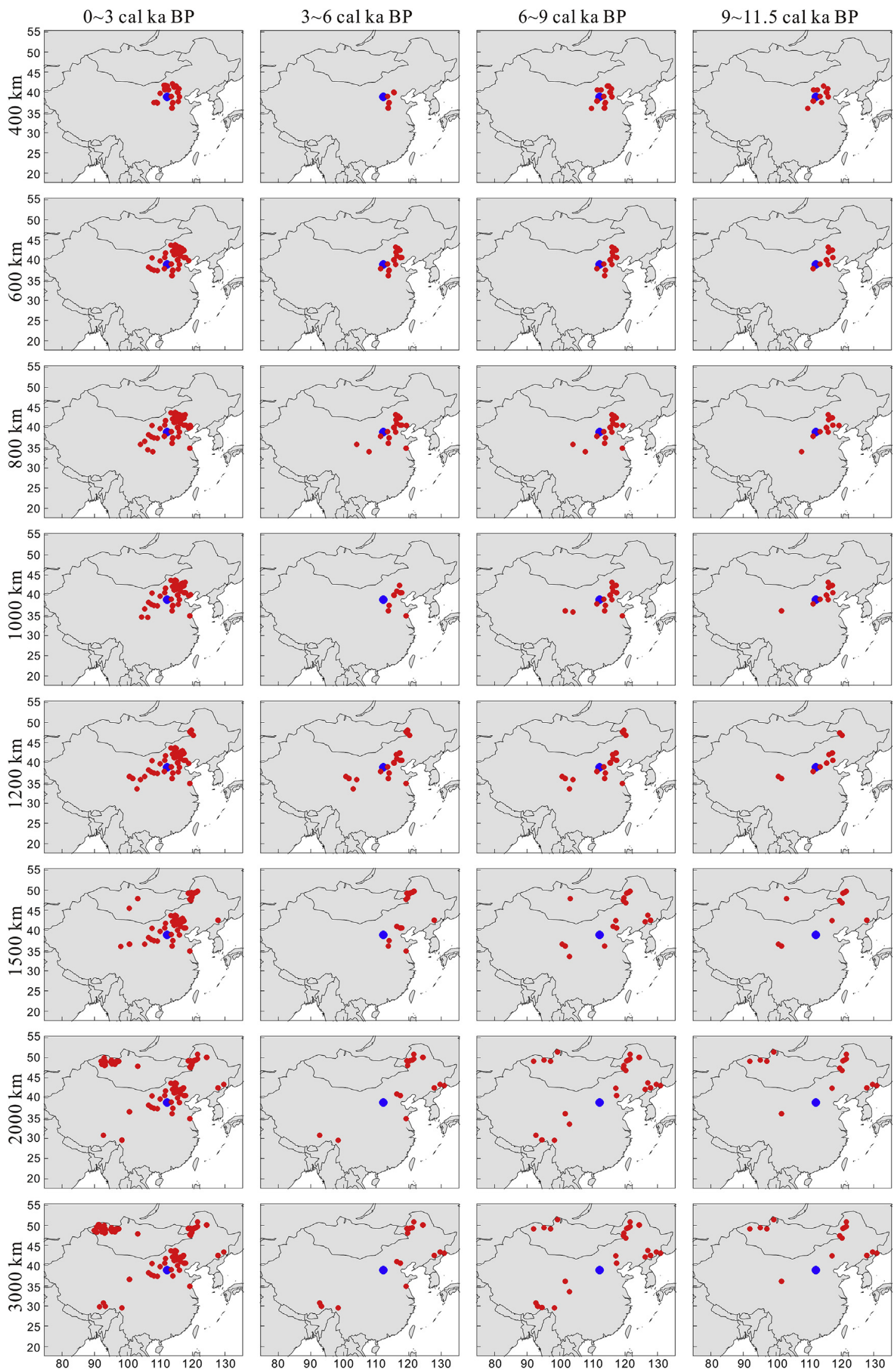

B

Fig. 4. (continued). 

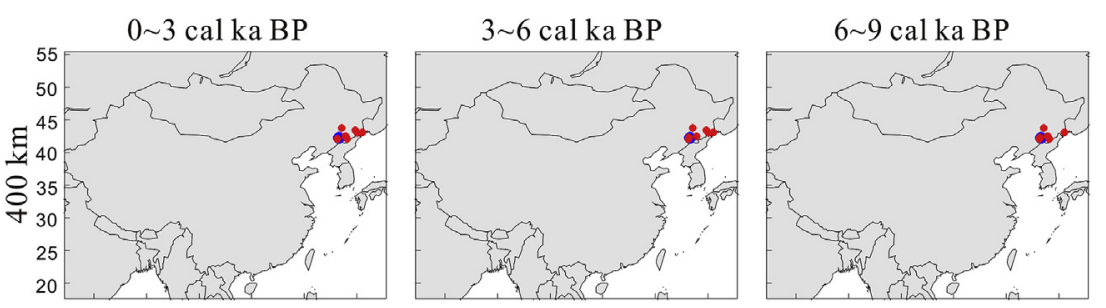

9 11.5 cal ka BP
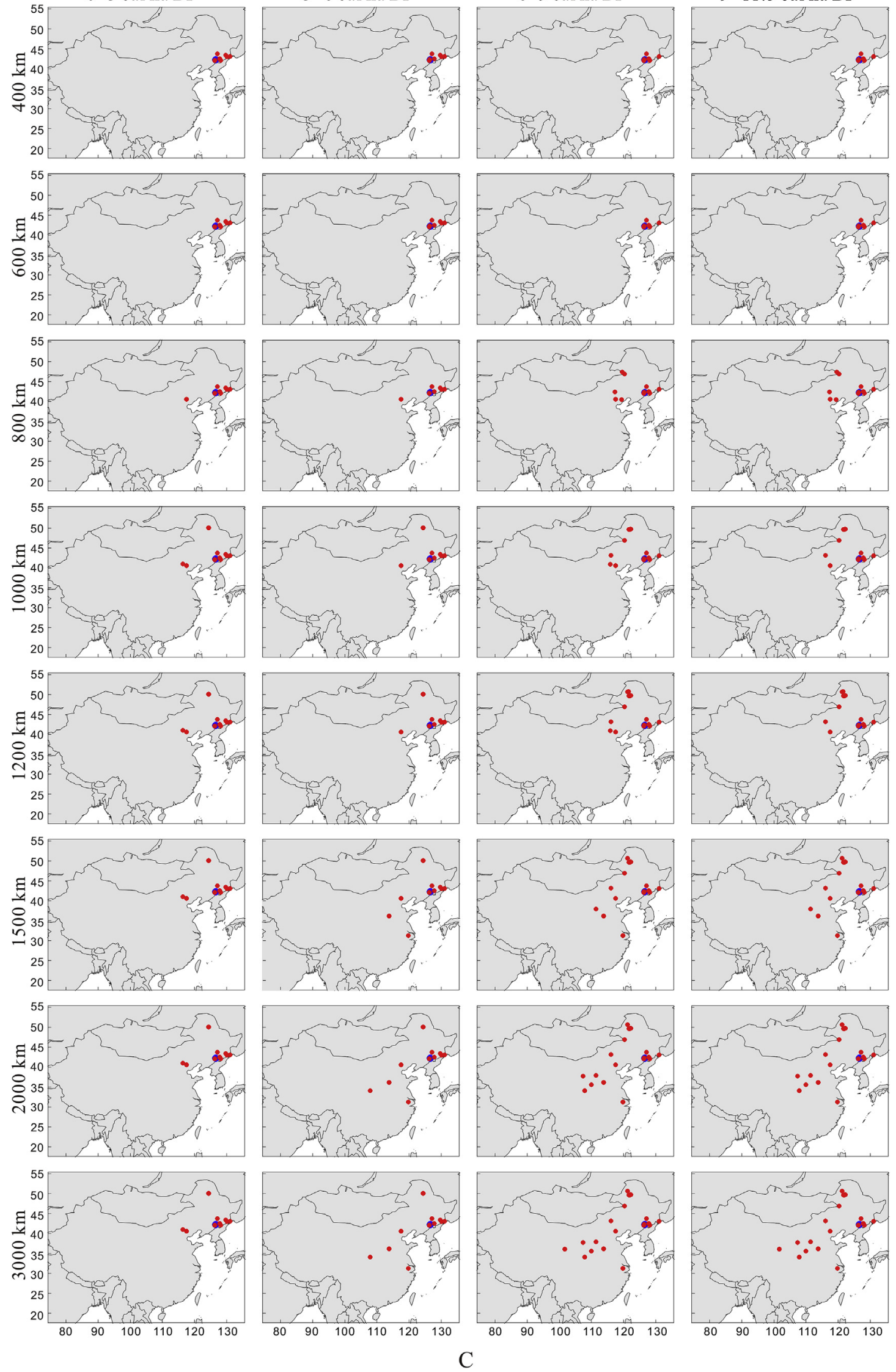

Fig. 4. (continued). 
which led to the reconstruction of low $\mathrm{P}_{\mathrm{ann}}$ (Fig. 3B). In contrast, the modern analogues in the $\leq 1200 \mathrm{~km}$ calibration-set are located to the south and east of Qinghai Lake (Fig. 4A) yielding high $\mathrm{P}_{\mathrm{ann}}$ (Fig. 3B). Picea is one of the most common tree taxa in both the early- and mid-Holocene pollen spectra from Qinghai Lake and their modern analogues from west Mongolia. Picea crassifolia is the dominant Picea species around Qinghai Lake, and the northern limit of its distribution area is south Inner Mongolia (Fang et al., 2011), while Picea obovata is the dominant Picea species in west Mongolia, and the southern limit of its distribution area is the Altai Mountains (Hilbig and Knapp, 1983). The different climate envelopes between the two Picea species as revealed by their disjunct distributions can explain the bias in reconstructions based on large calibration-sets that include both species. A similar phenomenon is noted in north-east Europe: a large calibration-set covering arctic tundra and steppe produces a larger bias than a small one omitting steppe sites, probably caused by the different climate envelopes of species (e.g. Poaceae) found in both communities (Salonen et al., 2011). In addition, our results confirm a previous suggestion that MAT is not a suitable method to use when the calibration-set has a large spatial extent (Birks et al., 2010; Juggins and Birks, 2012).

Our results indicate that, with both methods, the period of highest $\mathrm{P}_{\mathrm{ann}}$ (optimum) is also dependent on the spatial extent of the calibration-set. For example, the highest $P_{\text {ann }}$ for Gonghai Lake and Sihailongwan Lake when reconstructed by WA-PLS occurs at ca. 6-7 cal ka BP if calibration-sets (either circular or annular) of small or intermediate spatial extent $(<2000 \mathrm{~km})$ are used, while the highest $\mathrm{P}_{\mathrm{ann}}$ is shifted to ca. 3-4 cal ka BP when large-scale calibration-sets are used (Fig. 3A; Appendix 1). Quercus and Pinus are the dominant arboreal pollen taxa during the middle and late Holocene, respectively (Chen et al., 2015; Stebich et al., 2015). In the modern datasets these two taxa show contrasting trends in their weighted average optima (not shown) when increasing the spatial extent of the calibration set: while the WA optima of Pinus increases with size, it decreases for Quercus. We conclude that the observed shift in the optima is related to changes in the pollen/plant-precipitation relationship. Pinus tabuliformis is the most common Pinus species in northern China (location of Gonghai Lake) whereas Pinus sylvestris, Pinus pumila and Pinus koraiensis dominate in north-eastern China (location of Sihailongwan Lake). All these taxa have $P_{\text {ann }}$ preference ranges between ca. $500 \mathrm{~mm}$ and ca. $700 \mathrm{~mm}$ (Fang et al., 2011). The calibration-sets for Gonghai Lake and Sihailongwan Lake include the tropical areas of southern China ( $\geq 2000 \mathrm{~km}$ for Gonghai Lake; $3000 \mathrm{~km}$ for Sihailongwan Lake) characterised by high $\mathrm{P}_{\mathrm{ann}}$, where Pinus yunnanensis, Pinus kwangtungensis and Pinus massoniana are the dominant Pinus species, with $>1400 \mathrm{~mm}$ $P_{\text {ann }}$ preferences (Fang et al., 2011). In addition, during the Holocene, major Pinus species (e.g. Pinus tabuliformis, Pinus koraiensis, Pinus kwangtungensis) are unlikely to have had strong areal changes in eastern Asia as implied from genetic evidence (e.g. Tian et al., 2008; Wang and Gao, 2009; Qiu et al., 2011; Aizawa et al., 2012). In our case, the WA-optima for Quercus (together with other arboreal taxa such as Ulmus, Fraxinus and Juglans) on the $\mathrm{P}_{\text {ann }}$ gradient reduce markedly while those for Pinus rise when the calibration-sets extend from intermediate to large areas (results not shown). The highest $P_{a n n}$ inferred from intermediate-size calibration-sets thus occurs in the middle Holocene due to high Quercus abundance, while the highest $\mathrm{P}_{\mathrm{ann}}$ inferred with large calibration-sets occurs at ca. 3-4 cal ka BP because of the higher Pinus abundances. The $P_{\text {ann }}$ optima shifts are also revealed by the annular calibration-sets for Gonghai Lake and Sihailongwan Lake, which is further argument that the shifts in the optima are caused by the inclusion of tropical pollen sites into the calibration-set (Appendix 1). Such an effect would be much weaker if the Pinus haploxylon-type could have been taxonomically separated from the Pinus diploxylon-type, as has been done for Sihailongwan Lake, but has not for most samples in the calibration-set or the other two data-sets.

\subsection{How to select a suitable spatial extent of a calibration-set?}

Uniformitarianism, or more specifically, the "space-for-time" substitution, represents the basic concept for pollen-based climate reconstructions (Juggins and Birks, 2012; Blois et al., 2013). Our results indicate that the spatial extent of the calibration-set should be adapted to the potential climate gradient covered by the period of investigation. In our cases, the spatial extent of modern pollen sampling should be restricted to between ca. 1000- and $1500-\mathrm{km}$ radii around the target fossil site. Calibration-sets with less than $800 \mathrm{~km}$ radii are too small to include enough spatial variation in the modern pollen records to represent the temporal range shifts during the Holocene (Fig. 2A, B and C; Appendix 1). Calibration-sets with more than $1500 \mathrm{~km}$ radii include many heterogeneous pollen assemblages representing various climate types and vegetation types, which can cause a change in the pollen-climate relationship for regression-based approaches and may result in multiple analogues for analogue-based approaches. Based on the results of this study the following recommendations for setting up calibrationssets are made to improve the reliability of pollen-based climate reconstructions.

1) The available calibration-set should cover a reasonable spatial extent. On the one hand, the spatial pollen variation of the calibration-set should cover the temporal variation of the target fossil pollen record; but on the other hand, the calibration-set should be restricted spatially to form a homogenous pollenclimate relationship. Based on the case investigations, we propose that the spatial extent of a calibration-set should be larger than $1000 \mathrm{~km}$ in radius but no more than $1500 \mathrm{~km}$, for pollen records from northern China covering the Holocene.

2) The selection of the spatial extent of the modern dataset (the longest spatial distance of modern site to fossil site) used for calibration should be guided by the following measures inferred from the assessment and application of a series of calibrationssets with increasing spatial extent: $r^{2}$, RMSEP and RMSEP\% of calibration-set cross-validation, analogue quality test and a statistical significance test.

3) Information on modern and past distribution ranges (inferred from palaeo-genetic and macrofossil studies) should be used for the determination of the spatial extent of the calibration-set, particularly for taxa that are dominant. This will help one avoid the issue of multiple plant species that share the same pollen taxon (e.g. Pinus for Gonghai Lake and Sihailongwan Lake) and thus of having similar pollen assemblages produced under different climate conditions (e.g. multiple-analogues from west Mongolia for early-Holocene pollen samples from Qinghai Lake).

\section{Conclusions}

Repeated pollen-based reconstructions of past climate for three sites in northern China using pollen-climate calibration-sets of varying spatial extents reveal that the spatial extent of the calibration-set significantly influences the pollen-climate model performance; the quality of the modern analogues; and the patterns of climate reconstruction including absolute value, range, temporal trend and optimum. These effects are more pronounced in reconstructions using MAT than WA-PLS. Small-scale 
calibration-sets ( $<800 \mathrm{~km}$ radius in northern China) might fail to include enough spatial variation in the modern pollen assemblages to represent the temporal range shifts during the Holocene, while too large a scale calibration-set $(>1500 \mathrm{~km}$ radius in northern China) will likely include more taxa with notably different pollenclimate relationships. We conclude that the optimal spatial extent should be identified for each site individually based on the assessment of the calibration-set performance, the analogue quality and the characteristics of the reconstruction results as gained from analyses using calibration-sets with a broad range of spatial extent around the target fossil pollen record.

\section{Acknowledgements}

This research was supported by the German Research Foundation and PalMod project (BMBF). Richard J. Telford was supported partially by Norwegian Research Council FriMedBio project palaeoDrivers (213607). Jian Ni was supported by the National Key Research and Development Program of China (2016YFC0502101). Xingqi Liu was supported by the National Natural Science Foundation of China (No. 41572338) Yan Zhao was supported by National Key Research and Development Program of China (\#2016YFA0600501). Cathy Jenks helped with language editing.

\section{Appendix A. Supplementary data}

Supplementary data related to this article can be found at https://doi.org/10.1016/j.quascirev.2017.10.030.

\section{References}

Aizawa, M., Kim, Z.-S., Yoshimaru, H., 2012. Phylogeography of the Korean pine (Pinus koraiensis) in northeast Asia: inferences from organelle gene sequences. J. Plant Res. 125, 713-723.

Birks, H.J.B., 1998. Numerical tools in palaeolimnology - progress, potentialities, and problems. J. Paleolimnol. 20, 307-332.

Birks, H.J.B., Heiri, O., Seppä, H., Bjune, A.E., 2010. Strengths and weaknesses of quantitative climate reconstructions based on late-Quaternary biological proxies. Open Ecol. J. 3, 68-110.

Birks, H.J.B., Line, J.M., Juggins, S., Stevenson, A.C., ter Braak, C.J.F., 1990. Diatoms and pH reconstruction. Phil. Trans. R. Soc. Lond. B 327, 263-278.

Birks, H.J.B., Seppä, H., 2004. Pollen-based reconstructions of late-Quaternary climate in Europe - progress, problems, and pitfalls. Acta Palaeobot. 44, 317-334.

Blois, J.L., Williams, J.W., Fitzpatrick, M.C., Jackson, S.T., Ferrier, S., 2013. Space can substitute for time in predicting climate-change effects on biodiversity. Proc. Natl. Acad. Sci. U. S. A. (PNAS) 110, 9374-9379.

Cao, X.Y. Herzschuh, U., Telford, R.J., Ni, J., 2014. A modern pollen-climate dataset from China and Mongolia: assessing its potential for climate reconstruction. Rev. Palaeobot. Palynol. 211, 87-96.

Chen, F., Xu, Q., Chen, J., Birks, H.J.B., Liu, J., Zhang, S., Jin, L., An, C., Telford, R.J., Cao, X., Wang, Z., Zhang, X., Selvaraj, K., Lu, H., Li, Y., Zheng, Z., Wang, H., Zhou, A., Dong, G., Zhang, J., Huang, X., Bloemendal, J., Rao, Z., 2015. East Asian summer monsoon precipitation variability since the last deglaciation. Sci. Rep. 5, 11186. https://doi.org/10.1038/srep11186.

Ding, Y., Wang, Z., Sun, Y., 2008. Inter-decadal variation of the summer precipitation in East China and its association with decreasing Asian summer monsoon. Part I: observed evidence. Int. J. Climatol. 28, 1139-1161.

Fang, J.Y., Wang, Z.H., Tang, Z.Y., 2011. Atlas of Woody Plants in China: Distribution and Climate, vol. 1. Higher Education Press, Beijing and Springer-Verlag, Berlin).

Finsinger, W., Heiri, O., Valsecchi, V., Tinner, W., Lotter, A.F., 2007. Modern pollen assemblages as climate indicators in southern Europe. Glob. Ecol. Biogeogr. 16, $567-582$.

Furrer, R., Nychka, D., Sain, S., 2013. Fields: tools for spatial data. version 6.8. Available at: http://cran.r-project.org/web/packages/fields/index.html.

Herzschuh, U., 2006. Palaeo-moisture evolution at the margins of the Asian monsoon during the last 50 ka. Quat. Sci. Rev. 25, 163-178.

Herzschuh, U., Birks, H.J.B., Mischke, S., Zhang, C., Böhner, J., 2010. A modern pollenclimate calibration set based on lake sediments from the Tibetan Plateau and its application to a Late Quaternary pollen record from the Qilian Mountains. J. Biogeogr. 37, 752-766.

Hilbig, W., Knapp, H.D., 1983. Vegetationsmosaik und Florenelemente an der WaldSteppen-Grenze im Khentey-Gebirge (Mongolei). Flora 174, 1-89.

Hou, H.Y., 1983. Vegetation of China with reference to its geographical distribution.
Ann. Mo. Bot. Gard. 70, 509-549.

Huisman, J., Olff, H., Fresco, L.F.M., 1993. A hierarchical set of models for species response analysis. J. Veg. Sci. 4, 37-46.

Juggins, S., 2012. Rioja: analysis of Quaternary Science Data version 0.7-3. Available at: http://cran.r-project.org/web/packages/rioja/index.html.

Juggins, S., Birks, H.J.B., 2012. Quantitative environmental reconstructions from biological data. Data handling and numerical techniques. In: Birks, H.J.B. Lotter, A.F., Juggins, S., Smol, J.P. (Eds.), Tracking Environmental Change Using Lake Sediments, vol. 5. Springer, Dordrecht, pp. 431-494.

Kong, W., Swenson, L.M., Chiang, J.C.H., 2017. Seasonal transitions and the westerly jet in the Holocene East Asian summer monsoon. J. Clim. 30, 3343-3365.

Kucera, M., Weinelt, M., Kiefer, T., Pflaumann, U., Hayes, A., Chen, M.T., Mix, A.C., Barrows, T.T., Cortijo, E., Duprat, J., Juggins, S., Waelbroeck, C., 2005. Reconstruction of sea-surface temperatures from assemblages of planktonic foraminifera: multi-technique approach based on geographically constrained calibration data sets and its application to glacial Atlantic and Pacific Oceans. Quat. Sci. Rev. 24, 951-998.

Li, J., Dodson, J., Yan, H., Wang, W., Innes, J.B., Zong, Y., Zhang, X., Xu, Q., Ni, J., Lu, F., 2017b. Quantitative Holocene climatic reconstructions for the lower Yangtze region of China. Clim. Dyn. https://doi.org/10.1007/s00382-017-3664-3.

Li, J., Dodson, J., Yan, H., Zhang, D.D., Zhang, X., Xu, Q., Lee, H.F., Pei, Q., Cheng, B. Ni, J., Sun, A., Lu, F., Zong, Y., 2017a. Quantifying climatic variability in monsoonal northern China over the last 2200 years and its role in driving Chinese dynastic changes. Quat. Sci. Rev. 159, 35-46.

Li, J., Ilvonen, L., Xu, Q., Ni, J., Jin, L., Holmström, L., Zheng, Z., Lu, H., Luo, Y., Li, Y., Li, C., Zhang, X., Seppä, H., 2016. East Asian summer monsoon precipitation variations in China over the last 9500 years: a comparison of pollen-based reconstructions and model simulations. Holocene 26, 592-602.

Liu, J., Chen, J., Zhang, X., Li, Y., Rao, Z., Chen, F., 2015. Holocene East Asian summer monsoon records in northern China and their inconsistency with Chinese stalagmite $\delta^{18} \mathrm{O}$ records. Earth Sci. Rev. 148, 194-208.

Liu, X.Q., Shen, J., Wang, S.M., Yang, X.D., Tong, G.B., Zhang, E.L., 2002. A 16000-year pollen record of Qinghai Lake and its paleoclimate and paleoenvironment. Chin. Sci. Bull. 47, 1931-1936.

Oksanen, J., 2013. Gravy: gradient Analysis of Vegetation version 0.2-0. Available at: https://r-forge.r-project.org/R/?group_id=68.

Prentice, I.C., 1980. Multidimensional scaling as a research tool in Quaternary palynology: a review of theory and methods. Rev. Palaeobot. Palynol. 31, $71-104$.

Qiu, Y.X., Fu, C.X., Comes, H.P., 2011. Plant molecular phylogeography in China and adjacent regions: tracing the genetic imprints of Quaternary climate and environmental change in the world's most diverse temperature flora. Mol Phylogenet. Evol. 59, 225-244.

R Core Team, 2012. R: a Language and Environment for Statistical Computing. R Foundation for Statistic Computing, Vienna.

Rehfeld, K., Trachsel, M., Telford, R.J., Laepple, T., 2016. Assessing performance and seasonal bias of pollen-based climate reconstructions in a perfect model world. Clim. Past 12, 2255-2270.

Salonen, J.S., Ilvonen, L., Seppä, H., Holmström, L., Telford, R.J., Gaidamavicius, A. Stancikaite, M., Subetto, D., 2011. Comparing different calibration methods (WA) WA-PLS regression and Bayesian modelling) and different-sized calibration sets in pollen-based quantitative climate reconstruction. Holocene 22, 413-424.

Schettler, G., Liu, Q., Mingram, J., Stebich, M., Dulski, P., 2006. East-Asian monsoon variability between 15000 and $2000 \mathrm{cal}$. yr BP recorded in varved sediments of Lake Sihailongwan (northeastern China, Long Gang volcanic field). Holocene 16, 143-157.

Shen, C., Liu, K.B., Tang, L., Overpeck, J.T., 2006. Quantitative relationships between pollen rain and climate in the Tibetan Plateau. Rev. Palaeobot. Palynol. 140, $61-77$.

Stebich, M., Rehfeld, K., Schlütz, F., Tarasov, P.E., Liu, J., Mingram, J., 2015. Holocene vegetation and climate dynamics of NE China based on the pollen record from Sihailongwan Maar Lake. Quat. Sci. Rev. 124, 275-289.

Tao, S.Y., Chen, L.X., 1987. A review of recent research on the East Asian summe monsoon in China. In: Chang, C.P., Krishnamurti, T.N. (Eds.), Monsoon Meteorology. Oxford University Press, Oxford, pp. 60-92.

Telford, R.J., 2013. palaeoSig: significance tests for palaeoenvironmental reconstructions. version 1.1-2. Available at: http://cran.r-project.org/web/ packages/palaeoSig/index.html.

Telford, R.J., Birks, H.J.B., 2011. A novel method for assessing the statistical significance of quantitative reconstructions inferred from biotic assemblages. Quat. Sci. Rev. 30, 1272-1278.

Tian, F., Cao, X., Dallmeyer, A., Zhao, Y., Ni, J., Herzschuh, U., 2017. Pollen-climate relationships in time (9 ka, $6 \mathrm{ka}, 0 \mathrm{ka}$ ) and space (upland vs. lowland) in eastern continental Asia. Quat. Sci. Rev. 156, 1-11.

Tian, F., Herzschuh, U., Telford, R.J., Mischke, S., van der Meeren, T., Krengel, M., 2014. A modern pollen-climate calibration-set from central-western Mongolia and its application to a late glacial-Holocene record. J. Biogeogr. https://doi.org/ $10.1111 /$ jbi.12338.

Tian, S., Luo, L.C., Ge, S., Zhang, Z.Y., 2008. Clear genetic structure of Pinus kwangtungensis (Pinaceae) revealed by a plastid DNA fragment with a novel minisatellite. Ann. Bot. 102, 69-78.

Wang, M.B., Gao, F.Q., 2009. Genetic variation in Chinese pine (Pinus tabulaeformis), a woody species endemic to China. Biochem. Genet. 47, 154-164.

Wang, Y., Liu, X., Herzschuh, U., 2010. Asynchronous evolution of the indian and east asian summer monsoon indicated by Holocene moisture patterns in 
monsoonal central Asia. Earth Sci. Rev. 103, 135-153.

Williams, J.W., Shuman, B., 2008. Obtaining accurate and precise environmenta reconstructions from the modern analog technique and North American surface pollen dataset. Quat. Sci. Rev. 27, 669-687.

Xu, Q., Li, Y., Bunting, M.J., Tian, F., Liu, J., 2010. The effects of training set selection on the relationship between pollen assemblages and climate parameters: implications for reconstructing past climate. Palaeogeogr. Palaeoclimatol. Palaeoecol. 289, 123-133.

Zhu, J., Mingram, J., Brauer, A., 2013. Early Holocene aeolian dust accumulation in northeast China recorded in varved sediments from Lake Sihailongwan. Quat. Int. 290-291, 299-312. 